Z Rheumatol $2021 \cdot 80$ (Suppl 1):S1-S9 https://doi.org/10.1007/s00393-020-00785-4 Published online: 31 March 2020

(c) Springer Medizin Verlag GmbH, ein Teil von Springer Nature 2020

\section{Zusatzmaterial online}

The online version of this article (https://doi. org/10.1007/s00393-020-00785-4) contains further information on systematic literature searches. Article and supplementary material are available at www.springermedizin.de. Please enter the title of the article in the search field, the supplementary material can be found under "Supplementary contents".

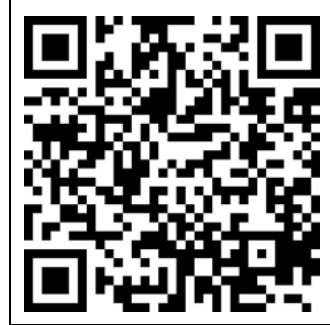

\section{Introduction}

Due to new evidence, antimalarials (AM) have experienced a renaissance in the treatment of Lupus erythematosus (SLE)

All authors for DGRh Kommission Pharmakotherapie.

The German version of this article can be found under https://doi.org/10.1007/s00393020-00751-0.

C. Fiehn ${ }^{1} \cdot$ T. Ness ${ }^{2} \cdot$ C. Weseloh ${ }^{3} \cdot$ C. Specker ${ }^{4} \cdot$ D. Hadjiski ${ }^{1}$ J. Detert ${ }^{5} \cdot K_{\text {K. Küger }}^{6} \cdot$ DGRh Kommission Pharmakotherapie

${ }^{1}$ Medical Center Baden-Baden and ViDia-Kliniken Karlsruhe, Practice for Rheumatology and Clinical Immunology, Baden-Baden, Germany

${ }^{2}$ Klinik für Augenheilkunde, Universitätsklinik Freiburg, Freiburg, Germany

${ }^{3}$ Deutsche Gesellschaft für Rheumatologie, Berlin, Germany

${ }^{4}$ Klinik für Rheumatologie und Klinische Immunologie, Kliniken Essen-Mitte, Essen, Germany

${ }^{5}$ Rheumatologisch-immunologische Arztpraxis, Templin, Germany

${ }^{6}$ Praxiszentrum St. Bonifatius, München, Germany

\title{
Safety management in treatment with antimalarials in rheumatology. Interdisciplinary recommendations on the basis of a systematic literature review
}

and are also used in the treatment of other rheumatic diseases. They have a protective effect on the frequency of disease episodes and organ damage caused by SLE, a good effect on cutaneous manifestations of LE, among other things, and lead to a reduction of cardiovascular events and mortality. Hydroxychloroquine (HCQ) is therefore recommended in the treatment of all SLE patients on a permanent basis [1]. In the treatment of rheumatoid arthritis (RA), the use of HCQ is an option in combination with methotrexate and sulfasalazine for a guideline-based therapeutic strategy [2]. Recent EULAR recommendations name HCQ as a therapeutic option that can be considered for treating patients with primary Sjögren's syndrome or antiphospholipid syndrome under certain circumstances [3, 4]. However, the two latter indications have so far not been approved in Germany. AM are usually welltolerated and rarely lead to severe unwanted effects. If they do appear though, it is important to identify them at an early stage. AM-induced retinopathy is most feared as it can lead to blindness in rare cases. Advances in ophthalmology have revealed new possibilities for early diagnosis. Yet, there are myopathies and car- diomyopathies as well as other rare and unwanted effects that can be observed under AM therapy. It can be difficult to correctly associate and diagnose them. The importance of AM in rheumatology and the new findings on early diagnoses of the toxicity of these drugs called for updated evidence-based recommendations on the safety management in AM treatment.

\section{Methods}

A systematic literature review of the Medline (PubMed) and Cochrane databases identified 1160 studies on the safety of AM therapy in rheumatology. In addition, a manual search was carried out. 67 particularly relevant publications were analyzed in more detail by measuring case numbers, their relevance for the issues in question and the methodical quality. The analyzed publications were prospective randomized studies on therapeutic questions (to study safety evaluations), prospective monitoring studies, retrospective case control studies, database analyses as well as systematic reviews. Case reports on rare unwanted events were listed and-in certain cases, such as AM-induced nephropathy-also 
ophthalmological

examinations within the

first 6 months after

starting treatment

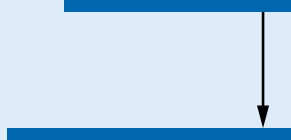

assessment of risk factors:

pre-existing makulopathy

renal insufficiency

(GFR<60ml/min)

adjuvant tamoxifen therapy

daily HCQ uptake of $>5 \mathrm{mg} / \mathrm{kg}$

$\mathrm{CQ}$ instead of HCQ therapy

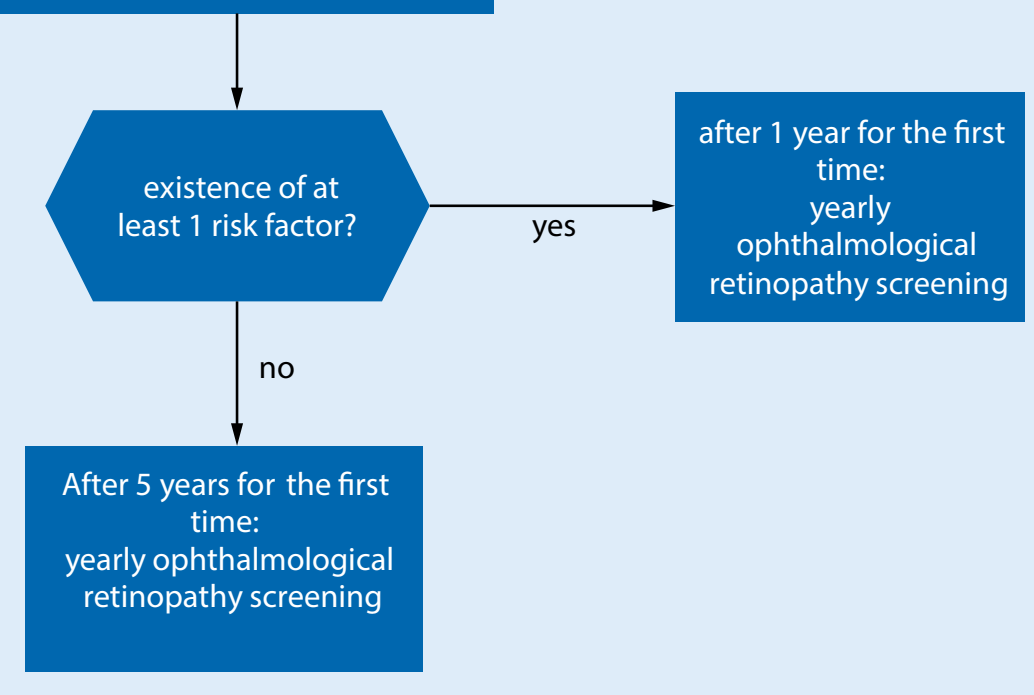

Fig. $1 \Delta$ Procedure to determine the frequency of retinopathy screenings. Retinopathy screenings always comprise an appropriate subjective and an objective method (usually automated perimetry and OCT). OCT ocular coherence tomography, GFR glomerular filtration rate, HCQ hydroxychloroquine, CQ chloroquine

analyzed in detail (see tabular list in the supplement). They were used for finding consensus-based recommendations in an interdisciplinary group of experts of the Deutsche Gesellschaft für Rheumatologie (DGRh, German Association for Rheumatology) in cooperation with the Deutsche Ophthalmologische Gesellschaft (DOG, German Ophthalmological Association). The levels of recommendation were systematically assigned in accordance with the 2009 procedures of the Oxford Centre for Evidence-Based Medicine in agreement with the authors. Every decision was unanimous during the consensus process.

Details on the systematic literature review with the PICO question, research criteria as well as a comprehensive reference list can be found in the supplement (www.springerlink.com).

\section{Results}

\section{Ocular screening for retinopathy}

HCQ and chloroquine (CQ) can be retinotoxic; the risk depends on how much and how long the medication is taken. In case of HCQ, the risk is much better assessed than in the case of CQ [5]. With an HCQ uptake of less than $5 \mathrm{mg}$ per $\mathrm{kg}$ of the patient's body weight per day, the retinopathy risk is defined as characteristic alterations shown in automated perimetry and/or optical co- herence tomography (OCT). It ranges from $<1 \%$ during the first 5 years of treatment to $<2 \%$ in the first 10 years of treatment and can rise up to ca. 10 to $20 \%$ after 20 years of treatment [5-9]. The risk of worsening conditions within one year after being diagnosed and discontinuing medication is below $1 \%$ in the first 10 years and at ca. $4 \%$ after 20 years [5]. Retinopathy, hence, is irreversible and may progress even after discontinuing the medication. However, it rarely leads to blindness. There are additional risk factors for developing retinopathy apart from the duration of the drug uptake [5-8]: 1. doses of HCQ of $>5 \mathrm{mg} / \mathrm{kg}$ body weight/day; 2 . functional renal disorders with a GFR of $<60 \mathrm{ml} / \mathrm{min}$; 3 . adjuvant tamoxifen therapy; 4. significant central photoreceptor damage (maculopathy) before staring treatment; 5. CQ-treatment $[8,9]$.

It is the aim of the ocular screening to detect retinopathy before it causes functionally relevant damage or before changes in the fundus are traceable in fundoscopy, such as the typical bullseye retinopathy. A basic ophthalmological check is recommended within the first 6 months of AM treatment to detect possible pre-existing modifications of the retina. Patients showing any of the risk factors mentioned above should then further undergo ophthalmological checkups on a yearly basis right from the start. Patients without any risk factors should start these after 5 years of treatment as developing an HCQ-induced retinopathy earlier is very unlikely due to the insufficiently cumulative dosage (- Fig. 1 ). If the situation changes within the first 5 years, e.g. if a tamoxifen therapy is started or a significant renal insufficiency manifests, check-ups should be done every year.

The ophthalmological examinations (basic and check-up) should comprise at least one appropriate subjective and one objective method respectively apart from a fundus examination with imaging. Appropriate methods are automated perimetry tests ( 10 degrees in diameter, 2 degrees of distance $=10-2$; for patients of Asian origin 24-2 or 30-2) as subjective methods [12, 13] and OCT [13-18], multifocal electroretinographies (mf-ERG) 
Z Rheumatol 2021 · 80 (Suppl 1):S1-S9 https://doi.org/10.1007/s00393-020-00785-4

๑) Springer Medizin Verlag GmbH, ein Teil von Springer Nature 2020

C. Fiehn · T. Ness · C. Weseloh · C. Specker · D. Hadjiski · J. Detert · K. Krüger · DGRh Kommission Pharmakotherapie

\section{Safety management in treatment with antimalarials in rheumatology. Interdisciplinary recommendations on the basis of a systematic literature review}

\section{Abstract}

Background. Antimalarial medication (AM) plays an important role in the treatment of rheumatic diseases.

Objective. Updated evidence-based recommendations on the safety management of rheumatological treatment with AM are presented.

Methods. A systematic literature search in the databases Medline (PubMed) and Cochrane identified 1160 studies on the safety of treatment with AM in rheumatology. In addition, a manual search was carried out and 67 publications considered to be particularly relevant by the authors were analyzed in more detail. These publications served as a basis for consensus-based recommendations.

Results. Treatment with AM in rheumatology should be carried out with hydroxychloroquine (HCQ) with a dosage not exceeding $5 \mathrm{mg} / \mathrm{kg}$ body weight/day. Patients should undergo a basic ophthalmological examination within the first 6 months of AM treatment. Preexisting maculopathy, renal insufficiency (glomerular filtration rate, GFR $<60 \mathrm{ml} / \mathrm{min}$ ), tamoxifen comedication, a daily dose of $>5 \mathrm{mg} / \mathrm{kg} \mathrm{HCQ}$ or treatment with chloroquine (CQ) show an increased risk for AM-induced retinopathy. These patients should undergo an annual ophthalmological check from the beginning of the treatment, whereas patients with no risk factors are recommended to start this only after 5 years of taking the medication. The ophthalmological examination should comprise at least both an appropriate subjective and an objective method and these are usually an automated visual field test and optical coherence tomography (OCT). A visual field test revealing a parafoveal sensitivity loss and an OCT showing a parafoveal circumscribed loss of the photoreceptor layer or focal interruptions of the structural line of the outer segment are signs of a possible AM retinopathy. Determination of creatine kinase (CK) and lactate dehydrogenase (LDH) in blood is appropriate to screen for cardiomyopathy and myopathy and should be checked before starting the treatment and then ca. every 3 months. The use of cardiac biomarkers, such as brain natriuretic peptide (BNP) or troponin in serum, electrocardiograph (ECG) or cardiac imaging should be considered depending on the situation. An intake of HCQ is safe during pregnancy and breastfeeding according to the current state of knowledge and is protective for mother and child in patients with systemic lupus erythematosus.

Conclusion. The updated recommendations on AM treatment in rheumatology in particular include a more rigorous measuring of doses, risk stratification in monitoring and defined ophthalmological examination methods to detect a possible retinopathy.

\section{Keywords}

Hydroxychloroquine · Chloroquine - Lupus erythematosus - Retinopathy - Ophthalmological examination

\section{Sicherheitsmanagement der Therapie mit Antimalariamitteln in der Rheumatologie. Interdisziplinäre Empfehlungen auf der Basis einer systematischen Literatur-Recherche}

\section{Zusammenfassung}

Hintergrund. Antimalariamittel (AM) haben eine große Bedeutung in der Therapie rheumatischer Erkrankungen.

Ziel dieser Arbeit. Es werden aktualisierte evidenzbasierte Empfehlungen zum Sicherheitsmanagement der rheumatologischen Therapie mit AM aufgezeigt.

Methodik. Durch eine systematische Literaturrecherche in den Datenbanken Medline (PubMed) und Cochrane wurden 1160 Arbeiten zur Sicherheit der Therapie mit AM in der Rheumatologie identifiziert. Ergänzend wurde eine Handsuche durchgeführt. Es wurden 67 von den Autoren als besonders relevant eingeschätzte Publikationen genauer analysiert. Diese dienen als Grundlage für konsensbasierte Empfehlungen.

Ergebnisse. Eine Therapie mit AM in der Rheumatologie sollte mit Hydroxychloroquin (HCQ) erfolgen und die Dosis von $5 \mathrm{mg} / \mathrm{kg}$ Körpergewicht/Tag nicht überschreiten. In den ersten 6 Monaten der Therapie mit AM ist eine augenärztliche Basisuntersuchung empfohlen. Vorbestehende Makulopathie,
Niereninsuffizienz (GFR [glomeruläre Filtrationsrate] $<60 \mathrm{ml} / \mathrm{min}$ ), TamoxifenBegleittherapie, Tagesdosen von $>5 \mathrm{mg} / \mathrm{kg}$ HCQ oder Therapie mit Chloroquin (CQ) gehen mit einem erhöhten Risiko für eine AM-induzierte Retinopathie einher. Diese Patienten sollten daher von Beginn an jährlich augenärztliche Kontrollen erhalten, während dies bei Patienten ohne Risikofaktoren erst ab 5 Jahren Einnahmedauer empfohlen wird. Die ophthalmologische Untersuchung sollte mindestens je eine geeignete subjektive und objektive Methode nutzen, in der Regel sind dies das automatisierte Gesichtsfeld (aGF) und die optische Kohärenztomographie (OCT). Anzeichen einer möglichen AMRetinopathie sind im aGF eine parafoveale Empfindlichkeitsabnahme und im OCT eine umschriebene Verdünnung der Photorezeptorschicht parafoveal und/oder fokale Unterbrechungen der Außensegmentstrukturlinie. Die Bestimmung der Kreatinkinase (CK) und Laktatdehydrogenase (LDH) im Blut ist als Screeninguntersuchung auf eine evtl. Myopathie oder Kardiomyopathie geeignet und sollte ca. 3-monatlich erfolgen. Der Einsatz von kardialen Biomarkern im Serum wie "brain natriuretic peptide" (BNP) oder Troponin, EKG (Elektrokardiogramm) oder kardiale Bildgebung sollte je nach Situation erwogen werden. Die Einnahme von HCQ ist in Schwangerschaft und Stillzeit nach gegenwärtigem Wissen sicher und bei Patientinnen mit systemischem Lupus erythematodes protektiv für Mutter und Kind. Fazit. Die aktualisierten Empfehlungen der Therapie mit AM in der Rheumatologie beinhalten v. a. strengere Dosisvorgaben, eine Risikostratifizierung im Monitoring sowie definierte augenärztliche Untersuchungsmethoden zur Erkennung einer evtl. Retinopathie.

\section{Schlüsselwörter}

Hydroxychloroquin · Chloroquin · Lupus erythematodes - Retinopathie . Ophthalmologische Untersuchung 
1 AM treatment in rheumatology should use hydroxychloroquine (HCQ) and not exceed the administration of $5 \mathrm{mg} / \mathrm{kg}$ body weight/d

2 Patients should undergo a basic ophthalmological examination within the first 6 months of AM-therapy

B

3 A pre-existing maculopathy, renal insufficiency (GFR $<60 \mathrm{ml} / \mathrm{min}$ ), an adjuvant tamoxifen therapy, a daily HCQ uptake of $>5 \mathrm{mg} / \mathrm{kg}$ body weight or CQ instead of HCQ therapy are risk factors for developing AM-induced retinopathy

$4 \quad$ Patients with an increased retinopathy risk (see 3) should get yearly ophthalmological check-ups from the beginning of therapy while patients without any risk factors are advised to start the examination interval only after 5 years of treatment

5 The examinations (basic and check-up) should comprise at least both an appropriate subjective and an objective method, usually automated perimetry and optical coherence tomography (OCT). Multifocal electroretinographies (mf-ERG) or fundus autofluorescence (FAF) are also appropriate objective methods

6 Retinopathy screenings should pay attention to a parafoveal sensitivity loss in the visual field test and a parafoveal circumscribed loss of the photoreceptor layer or focal interruptions of the structural line of the outer segment in the OCT as they are indicators for AM retinopathy

7 A dose readjustment to a maximum of $3 \mathrm{mg} / \mathrm{kg}$ body weight for a GFR of $<30 \mathrm{ml} / \mathrm{min}$ is necessary in case of renal insufficiencies

8 Patients should undergo blood tests for CK and LDH levels before starting the therapy and then ca. every 3-6 months. These are appropriate screening examinations for finding myopathies or cardiomyopathies. If necessary, aldolase may additionally be screened in serum. An EMG or cardiac biomarkers, such as troponin or BNP, as well as ECG screenings and cardiac imaging are appropriate methods

$9 \mathrm{HCQ}$, in accordance with current knowledge, is safe during pregnancy and breastfeeding and treatment should be B continued if indicated

AM antimalarials, GFR glomerular filtration rate, CQ chloroquine, HCQ hydroxychloroquine, OCT optical coherence tomography, $C K$ creatinine kinase, $L D H$ lactat dehydrogenase, EMG elektromyography, BNP brain natriuretic peptide, ECG electrocardiography

$[13,19-21]$ or fundus autofluorescence (FAF) [22] as objective methods. The authors believe the OCT to be the most available objective method that will be used most frequently in practice.

Inappropriate retinopathy screening methods are sole fundus examinations with or without imaging, fluorescein angiography, full-field ERG, color vision tests or electro-oculography (EOG), as they are unable to detect early modifications-only advanced modifications at best [13].

Findings that are characteristic for AM retinopathy are listed in $\bullet$ Table 1 . If there are only little or questionable indications for the disease, monitored treatment can be continued after 6-12 months as progression is slow. Pathological findings from automated perimetry or mfERG should be checked and confirmed after 4-6 weeks. Examinations on a more frequent basis than every 6 months, however, are not useful. Whether to discontinue AM treatment or not, hence needs to be decided by ophthalmologists and rheumatologists together. An additional check of the findings at a special- ized ophthalmological center can then also be taken into consideration.

The recommendations on the frequency and methods of ocular screenings mentioned above are in accordance with the ones provided by the US-American as well as the British ophthalmological associations $[23,24]$.

\section{AM selection and dosage}

AM treatment with HCQ in rheumatology is recommended with a maximum uptake of $5 \mathrm{mg} / \mathrm{kg}$ body weight (actual weight) as the risk of developing retinopathy considerably increases with higher doses, as described above $[5,8]$. The optimum weight does not apply. CQ shall only be administered in exceptional cases as there are clear indications for a higher rate of retinopathies and of cardiac and muscular side effects $[25,26]$ in comparison to HCQ treatment $[10,11]$. There is the assumption that CQ might be more toxic as the administered doses are relatively too high. Therefore, a limit of $\leq 2.3 \mathrm{mg} / \mathrm{kg}$ body weight per day for a safe CQ uptake was determined [23] which only derives from extrapolation of phar- macodynamic data in comparison with toxic doses of hydroxychloroquine. It is also unclear if this dose would have any therapeutic effect. There is much more data available on HCQ, in particular on safety, which is why the authors refrain from recommending the use of CQ in rheumatology. CQ is no longer sold in Germany so that prescriptions would have to be done via pharmacies abroad anyway.

\section{Readjustment of doses for patients with renal insufficiency}

Renal drug excretion applies for about $40-50 \%$ of $\mathrm{AM}$ and renal insufficiency with an estimated GFR of $<60 \mathrm{ml} / \mathrm{min}$ is a retinopathy risk factor $[5,8]$. Pharmacological measurements, nevertheless, yield contradictory results on the impact of the renal function on blood levels of HCQ [27, 28]. A retrospective cohort study of a US renal database (USRDSRenal Data System) identified 2048 patients suffering from end-stage renal insufficiency that were given HCQ [29]. The medium HCQ dose was $321 \mathrm{mg}$ (between 58-2000 mg). This shows that 
Table 2 Recommended ophthalmological examination methods for retinopathy screenings under AM treatment and findings suspecting AM retinopathy

\begin{tabular}{|c|c|}
\hline Method & Findings reports suspecting AM retinopathy \\
\hline \multicolumn{2}{|l|}{ Subjective method } \\
\hline Automated perimetry tests ${ }^{\mathrm{a}}$ & Parafoveal loss of sensitivity ${ }^{b}$ \\
\hline \multicolumn{2}{|l|}{ Objective methods } \\
\hline \multirow[t]{2}{*}{ OCT } & Circumscribed parafoveal loss of the photoreceptor layer \\
\hline & Focal interruptions of the structural line of the outer segment \\
\hline \multirow[t]{2}{*}{ FAF } & Local parafoveal increased autofluorescence (early modifications) \\
\hline & Reduced autofluorescence (late modification) \\
\hline mfERG & Parafoveal loss of receptor response \\
\hline \multicolumn{2}{|c|}{$\begin{array}{l}\text { There should always be at least one subjective and one objective examination method } \\
\text { Automated perimetry, OCT optical coherence tomography, mfERG multifocal electroretinographies, } \\
\text { FAF fundus autofluorescence } \\
{ }^{a} 10 \text { degrees in diameter, } 2 \text { degrees of distance }=10-2 \text { (except for patients of Asian origin) } \\
\text { b As a subjective method, automated perimetry screenings have a certain variability; when measuring } \\
\text { a defect for the first time, the test should therefore be repeated }\end{array}$} \\
\hline
\end{tabular}

there was no dose readjustment in cases of end-stage renal insufficiency. There is no data available on whether the HCQ uptake needs to be stopped in case of advanced renal insufficiency. Considering the fact that the administration of HCQ is of particular importance for patients suffering from SLE and renal dysfunctions, the consensus group recommends a readjustment of HCQ doses only for a GFR of $<30 \mathrm{ml} / \mathrm{min}$ by administering a maximum of $3 \mathrm{mg} / \mathrm{kg}$ body weight. For a patient with a weight of $63 \mathrm{~kg}$ this would mean a dose of $200 \mathrm{mg} \mathrm{HCQ} / \mathrm{d}$. The dosage can even be continued during hemodialysis. If the HCQ dosage does not exceed $200 \mathrm{mg} / \mathrm{d}$, the drug should be given as intermittent administration (e.g. $3 \times$ per week), so that the medium daily uptake corresponds with the target dose.

\section{Nephrotoxicity}

Nephrotoxicity is a very rare complication in AM therapy only described in single case reports (supplement). Patients mostly develop a progressive renal dysfunction after several years of medication. Renal biopsies show phospholipid accumulations in the glomeruli. These modifications are difficult to distinguish from the ones occurring under Morbus Fabry, which is why renal AM damage can easily be confused with Morbus Fabry. The renal function can improve again after stopping treatment in case of AM nephropathy.

\section{Myopathies}

Myopathies were described in some single case report and in two prospective cohort studies [30, 31]. While one of the studies only reported one case (with CQ-therapy) out of 350 patients monitored over 8 years' time [30], the other study revealed this complication occurring in 22 out of 119 patients [31]. 93\% of these patients were administered CQ and only a few were given HCQ. Patients were diagnosed on average after 40 months (span: 6 to 192 months) after beginning treatment. All of the 22 patients had persistently increased muscle enzymes in their blood tests; 19 of the $22(86 \%)$ showed increased lactate dehydrogenase (LDH), 7 of the 22 (32\%) increased creatine kinase $(\mathrm{CK})$ as well as 3 of the $22(14 \%)$ increased aldolase levels. 8 patients suffered from muscle weakness, and only in these cases the electromyogram (EMG) showed myopathy patterns. 15 of the 22 cases are histologically proven. Optical microscopy showed pathological findings in only 3 of the 15 patients, but an electron microscopic examination revealed very characteristic vacuoles ("myeloid and curvelinear bodies") in the muscles of all patients. All symptomatic patients improved their conditions during the study after stopping the therapy. Single case reports with advanced AM-induced myopathies leading to death can, however, also be found in literature (case reports, see supplement).

The frequency of clinically manifest myopathies under an adequate HCQ dose is hence unknown; this type of complication is probably extremely rare.

The authors of this recommendation consider it advisable to determine CK and $\mathrm{LDH}$ as a myopathy screening (as well as for cardiomyopathies, see below) before starting the treatment and then repeat the test in an interval of ca. 3 to 6 months. If need be, aldolase may also be screened in serum. An EMG screening is appropriate in case of muscle weakness. Muscle biopsies with an electro microscopic examination of the biopsy material are considered the gold standard in diagnostics. The recommended diagnostic procedures are described in • Table 3.

\section{Neurological and psychiatric toxicity}

A systematic review was used to describe 7 cases of psychoses [32], which mostly occurred, however, in combination with prednisolone and almost all (7 of 8) under CQ uptake. Manifestation was independent of the duration of the administration (span of 5 days to 8 years after starting AM therapy); all of them were reversible. Additionally, polyneuropathies were described in a total of 7 cases; these also occurred under CQ uptake and independently of the duration, all reversible after stopping therapy (case reports, see supplement).

In accordance with expert information, HCQ reduces the seizure threshold and can weaken the effects of an anti-convulsive therapy. There are no publications to be found on this. Furthermore, due to weakening the effects of neostigmine or pyridostigmine, HCQ is supposed to interact in myasthenia gravis therapy. In cases of patients suffering from cerebral seizures or myasthenia, AM treatment must therefore be coordinated with the attending neurologist.

\section{Impairments of the hearing}

Impairments of the hearing were described in a pharmacovigilance data 
Table 3 Guiding symptoms, findings and recommended diagnostic procedures for diagnosing AM-induced myo- and cardiomyopathies

\begin{tabular}{|c|c|c|c|c|}
\hline $\begin{array}{l}\text { Typical } \\
\text { guiding } \\
\text { symptom }\end{array}$ & Lab test results & $\begin{array}{l}\text { Technical examina- } \\
\text { tions }\end{array}$ & $\begin{array}{l}\text { Confirming } \\
\text { diagnoses }\end{array}$ & $\begin{array}{l}\text { Reversi- } \\
\text { bility }\end{array}$ \\
\hline \multicolumn{5}{|l|}{ Myopathy ${ }^{\mathrm{a}}$} \\
\hline $\begin{array}{l}\text { Muscle weak- } \\
\text { ness (only in } \\
\text { ca. } 50 \% \text { of } \\
\text { cases) }\end{array}$ & $\begin{array}{l}\text { Increased LDH } \\
(86 \%), \text { CK (36\%) } \\
\text { and aldolase levels } \\
(14 \%)\end{array}$ & $\begin{array}{l}\text { EMG (in case of muscle } \\
\text { weakness always with } \\
\text { myopathy patterns) }\end{array}$ & $\begin{array}{l}\text { Muscle biopsy } \\
\text { with electron } \\
\text { microscopic } \\
\text { examination }\end{array}$ & $\begin{array}{l}\text { Possibly } \\
100 \% \\
\text { with early } \\
\text { diagnosis }\end{array}$ \\
\hline \multicolumn{5}{|c|}{ Cardiomyopathy $^{\mathrm{b}}$} \\
\hline $\begin{array}{l}\text { Cardiac insuf- } \\
\text { ficiency }\end{array}$ & $\begin{array}{l}\text { Increase in tro- } \\
\text { ponin I (100\%), } \\
\text { CK and BNP levels } \\
\text { (88\% repectively) }\end{array}$ & $\begin{array}{l}\text { Cardiac MRI with spec. } \\
\text { findings of ventricular } \\
\text { hypertrophy, ECG block } \\
\text { pictures }(75 \%)\end{array}$ & $\begin{array}{l}\text { Myocardial } \\
\text { biopsy or car- } \\
\text { diac MRI }\end{array}$ & $\begin{array}{l}\text { Reversible } \\
\text { for } 7 \text { out } \\
\text { of } 8\end{array}$ \\
\hline \multicolumn{5}{|c|}{ 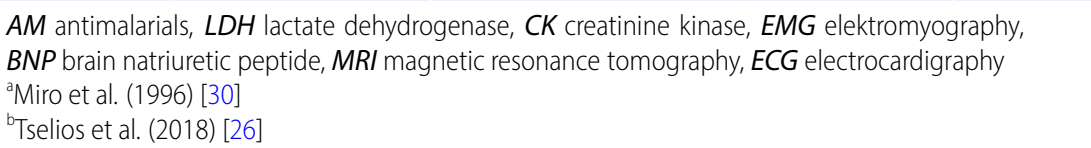 } \\
\hline
\end{tabular}

base analysis for the cases of $61 \mathrm{AM}$ patients, out of which 33 received HCQ therapy [33]. $8 \%$ showed a hearing reduction, $23 \%$ a loss of hearing and $24 \%$ suffered from tinnitus. It was, however, only in $5 \%$ of the patients that a correlation with $\mathrm{AM}$ medication was considered probable. This presumed toxicity occurred independently from the duration of uptake and was reversible in 59 of the 61 patients after discontinuing the medication.

\section{Cardiomyopathies and other unwanted cardiac effects}

AM cardiotoxicity is rare, but potentially dangerous. Paramount in this respect are possible disturbances of conduction or cardiomyopathies, that originate from phospholipid accumulations in the muscle tissue just as in case of myopathies. This results in myocardial hypertrophy with conduction disturbances and, possibly, indications of a cardiac insufficiency.

A recent meta-analysis of 127 cases showed that conduction disturbances, $\mathrm{AV}$, left or right bundle branch or complete heart block in particular, were the most frequent cardiac toxicity in $85 \%$ of all patients with unwanted cardiac effects [25]. These occurred on average after 7 years, but with a wide variability (3 days to 35 years). $60 \%$ of the patients were given CQ and 40\% HCQ. Only for $27 \%$ cardiac insufficiency was the main clinical symptom. After stopping medication, symptoms improved in $45 \%$, $13 \%$ showed irreversible damage of the heart and $13 \%$ died of it.

It is not certain if disturbances of the conduction of the heart can also be measured in large numbers without cardiomyopathy under HCQ therapy following the recommendations. A cross-sectional study examined 85 patients with an average HCQ uptake of 40 months and without showing clinical signs of a cardiomyopathy by means of an electrocardiogram (ECG) [34]. 3 cases (3.6\%) were identified with branch-block pictures; there was no difference in the rate from what was expected for the normal population. This is in contrast to an older examination in which the rate of cardiac conduction disturbances was at $17.5 \%$, but patients had mostly received CQ [35].

According to expert information, hydroxychloroquine can extend the QT interval and should hence not be administered with other drugs causing cardiac dysrhythmia, such as amiodarone and moxifloxacin.

The manifestation of an AM-induced cardiomyopathy has recently been described in very detail by an analysis of all 8 cases of a large lupus center [26]. 6 of the 8 patients had received HCQ and only 2 of them were given CQ. The medium AM therapy duration was 22 years (span: 9-45). All of the 8 patients showed increased troponin I levels, 7 showed either increased CK or brain natriuretic peptide (BNP) levels respectively and in only 6 of the 8 patients the ECG revealed pathological findings, then with block pictures. In case of all of the patients, a ventricular hypertrophy was detected in the ECG. The diagnosis of 3 of the 8 patients was confirmed by myocardial biopsy with an electron microscopic examination. Accumulations of myeloid cells were detected, i.e. the same findings that appear in biopsy material of the skeletal muscles in cases of AM myopathy. The 5 patients without histological confirmations had cardiac MRIs showing typical findings of a ventricular hypertrophy with or without atrial enlargement as well as a late gadolinium accumulation with a non-vascular image. The findings are assumed to be typical for AM cardiomyopathies.

With respect to the data described above, the authors recommend determining CK (and LDH) in serum as cardiomyopathy (and myopathy, see above) screenings before starting therapy and then ca. every 3 months. Additional cardiac biomarkers such as troponin I or BNP can be determined in serum if necessary. In cases of suspected cardiomyopathy or arrhythmia, in particular, patients should additionally get an ECG and cardiac imaging, ideally a cardiac MRI. Myocardial biopsies with electron microscopic examinations of the biopsy material are considered the gold standard for diagnosing (diagnostic procedures see - Table 3).

\section{Hyperpigmentation and other skin reactions}

A cross-sectional study including $41 \mathrm{pa}-$ tients that had taken HCQ and got an intensive dermatological examination revealed 12 cases of hyperpigmentation of the skin; these occurred most frequently on the lower extremities, but also on the face and the palate [36]. The medium duration of HCQ uptake was 32 months. The uptake of oral anticoagulants and thrombocyte aggregation inhibitors were predictors of this type of complication, and some of the patients had ecchymoses caused by micro traumas beforehand. Dyspigmentations as well as allergic skin rash, even exfoliative dermatitis, were also found in different retrospective stud- 
ies on AM therapy (see supplement). It is unknown whether the hyperpigmentations are reversible after stopping the medication.

\section{AM safety during pregnancy and breast feeding}

Congenital malformations are no more frequent under hydroxychloroquine than among the normal populations. Several cohort studies monitoring mothers and their children, of whom the mothers were administered the recommended AM dose during pregnancy and breast feeding, showed that neither ocular or auricular damage nor malformations of the eyes and ears could be detected in the fetuses or infants [37-39]. Therefore, HCQ therapy can be continued during pregnancy and breast feeding. The benefits of continuing HCQ therapies during pregnancy in cases of SLE have been proven several times; hence, the authors strongly recommend this for SLE patients.

\section{Other precautions}

Glucose 6 phosphate dehydrogenase deficiency is a contraindication of AM therapy according to expert information. Hydroxychloroquine can, in addition, supposedly enhance the effectiveness of medications reducing blood sugar levels, which may then lead to severe hypoglycemia. A reduction of insulin or other antidiabetics may therefore become necessary. Expert information speaks of an increase in the effect of cyclosporine A. The importance in practice and the extent of the interaction, however, are unknown. There are still a number of further interactions mentioned in the expert information that are mostly associated with groups of drugs that are rarely administered today. In doubt, physicians should seek advice in the expert information and take it into account.

Hydroxychloroquine is not an immunosuppressant drug, which is why there are no contraindications or specific warnings with regard to live vaccines [40]. Inactivated vaccines show no restrictions in effectiveness.

\section{Discussion}

The present work aims at giving practical recommendations on AM therapy management to guarantee the highest safety standards possible without compromising the benefits of AM use. The rare cases of cardiomyopathies, for instance, caused by AM have to be regarded in the context of a clear reduction in the frequency of severe cardiovascular events due to AM in the same group of patients. Still, it is important to stay attentive and purposeful to decrease the rate of complications and to be able to make early diagnoses.

We worked with a systematic literature review and used an interdisciplinary consensus process to set up these recommendations, including rheumatologists, ophthalmologists and methodologists.

First of all, we found it remarkable that literature hardly describes any absolute contraindications for starting a new AM therapy; the administration of HCQ, for example, can even be continued in reduced doses in cases of advanced renal insufficiency. There are no invariable characteristics in patients, except a pre-existing glucose 6 phospatase deficiency, that would prohibit therapeutic treatment under the corresponding indication; although, special attention needs to be paid to certain comorbidities. It was possible to furthermore develop strategies to reduce the risk of AM-induced retinopathy; i.e. choosing HCQ as the only recommended AM drug as CQ practically always showed considerably higher rates of toxicities compared with HCQ, and limiting HCQ doses to a maximum of $5 \mathrm{mg} / \mathrm{kgKG}$ per day allowing to clearly reduce retinopathies in comparison with higher doses. This recommendation particularly applies for patients between 65 and $80 \mathrm{~kg}$ body weight as they would have received $400 \mathrm{mg} \mathrm{HCQ/d}$, but who are now administered $200 \mathrm{mg}$ and $400 \mathrm{mg}$ alternately (doses rounded down).

The recommendations of risk stratifications for deciding whether to have patients undergo a yearly ophthalmological check-up from the beginning of therapy or only after 5 years of uptake are also new. These recommendations are in accordance with the recently published
British and US-American [23, 24] ophthalmological ones. The reason for risk stratification is that patients not carrying any risk factors extremely rarely develop retinopathies within the first 5 years of therapy $[5,8]$. After 5 years, however, to meet the recommendations, the ophthalmological screenings then need to be technically much more extensive than that used to be the case.

The aim of the ophthalmological examinations is to recognize AM retinopathies before they cause functionally relevant damage. Therefore, using one subjective and one objective examination method is appropriate. Usually, an automated perimetry test is used as a subjective method. As for the objective one, there are several possibilities; the optical coherence tomography (OCT) surely is the most practicable one for ophthalmologists and most frequently available. Yet, OCT is not an obligatory part of the statutory health care services for this indication. Methods unable to detect early modifications should not be used. This updated recommendation hence also leads to the fact that only ophthalmologists having the respective equipment at their disposal should do these examinations.

- Table 2 lists findings indicating AM-induced retinopathy for all recommended methods of retinopathy screenings. This is meant to facilitate and standardize making the decision whether to stop AM therapy or not. As important as it is to comply with treatment safety standards, it is also important to avoid an unfounded end to AM therapy. The decision whether to stop AM therapy should therefore only be made by an ophthalmologist and a rheumatologist together. If need be, a cross-check of the ophthalmological findings by a specialized center should be taken into consideration.

AM-induced retinopathy is rare, but still it is a much feared complication in AM therapy. The screening for other organ toxicities, in particular for cardiomyopathies and myopathies, is much less complicated, also due to the extraordinary rareness of these complications. In contrast to retinopathy, these manifestations are mostly reversible after discon- 
tinuing AM therapy (see • Table 3), although they are definitely dangerous at an advanced stage. We recommend getting tested in an interval of ca. 3 to 6 months of $\mathrm{CK}$ and $\mathrm{LDH}$ in serum as a basal screening for AM-induced myopathies. The use of cardiac biomarkers in serum, such as BNP or troponin, as well as ECG examinations or cardiac imaging should be taken into consideration depending on the situation. Within the small number of cases with indications of AM-induced myopathies, the EMG revealed pathological findings that need confirmation by biopsies in cases of muscle weakness. Myocardial and muscle biopsies, considered the gold standard in diagnostics, will only become necessary in very few cases. It is particularly important to sharpen the physicians' eyes and draw their attention to potential guiding symptoms and findings of organ toxicities in AM therapy. Procedures to detect guiding findings in case of cardiomyo- and myopathies are listed in $\bullet$ Table 3.

To sum up, we can state that AM therapy-today more than ever-has become an important part of therapy in rheumatology, especially with views to SLE. The treatment on the whole is safe and toxicities are very rare. The new recommendations are meant to help continuously reduce the risk of unwanted effects and to detect retinopathies as well as other unwanted effects as early as possible.

\section{Corresponding address}

\section{Prof. Dr. med. C. Fiehn}

Medical Center Baden-Baden and ViDia-

Kliniken Karlsruhe, Practice for Rheumatology and Clinical Immunology

Beethovenstr. 2, 76530 Baden-Baden, Germany c.fiehn@rheuma-badenbaden.de

\section{Compliance with ethical guidelines}

Conflict of interest. C. Fiehn, T. Ness, C. Weseloh, C. Specker, D. Hadjiski, J. Detert and K. Krüger declare that they have no competing interests.

For this article no studies with human participants or animals were performed by any of the authors. All studies performed were in accordance with the ethical standards indicated in each case.
The supplement containing this article is not sponsored by industry.

\section{References}

1. Fanouriakis A, Kostopoulou M, Alunno A et al (2019) 2019 update of the EULAR recommendations for the management of systemic lupus erythematosus. Ann Rheum Dis 78:736-745

2. Fiehn C, Holle J, Iking-Konert C et al (2018) S2eLeitlinie: Behandlung der rheumatoiden Arthritis mit krankheitsmodifizierenden Medikamenten. ZRheumatol 77(2):35-53

3. Ramos-Casals M, Brito-Zerón P, Bombardieri S et al (2020) EULAR recommendations for the management of Sjögren's syndrome with topical and systemic therapies. Ann Rheum Dis 79(1):3-18. https://doi.org/10.1136/annrheumdis-2019216114

4. Tektonidou MG, Andreoli L, Limper M et al (2019) EULAR recommendations for the management of antiphospholipid syndrome in adults. Ann Rheum Dis 78(10):1296-1304

5. Melles RB, Marmor MF (2014) The risk of toxic retinopathy in patients on long-term hydroxychloroquine therapy. JAMA Ophthalmol 132:1453-1460

6. Mavrikakis I, Sfikakis PP, Mavrikakis E et al (2003) The incidence of irreversible retinal toxicity in patients treated with hydroxychloroquine: a reappraisal. Ophthalmology 110:1321-1326

7. Mavrikakis M, Papazoglou S, Sfikakis PP et al (1996) Retinal toxicity in long term hydroxychloroquine treatment. Ann Rheum Dis 55:187-189

8. Wolfe F, Marmor MF (2010) Rates and predictors of hydroxychloroquine retinal toxicity in patients with rheumatoid arthritis and systemic lupus erythematosus. Arthritis Care Res 62:775-784

9. Aletaha D, Kapral T, Smolen JS (2003) Toxicity profiles of traditional disease modifying antirheumatic drugs for rheumatoid arthritis. Ann Rheum Dis 62:482-486

10. Finbloom DS, Silver K, Newsome DA et al (1985) Comparison of hydroxychloroquine and chloroquine use and the development of retinal toxicity. J Rheumatol 12:692-694

11. Aviña-Zubieta JA, Galindo-Rodriguez G, NewmanS et al (1998) Long-term effectiveness of antimalarial drugs in rheumatic diseases. Ann Rheum Dis 57:582-587

12. Hart WM, Burde RM, Johnston GP et al (1984) Static perimetry in chloroquine retinopathy. Perifoveal patterns of visual field depression. Arch Ophthalmol 102:377-380

13. Cukras C, Huynh N, Vitale S et al (2015) Subjective and objective screening tests for hydroxychloroquine toxicity. Ophthalmology 122:356-366

14. Rodriguez-Padilla JA, Hedges TR et al (2007) Highspeed ultra-high-resolution optical coherence tomography findings in hydroxychloroquine retinopathy. Arch Ophthalmol 125:775-780

15. Allam RSHM, Abd-Elmohsen MN, Khafagy MM et al (2015) Spectral-domain optical coherence tomography of preclinical chloroquine maculopathy in Egyptian rheumatoid arthritis patients. J Ophthalmol 2015:292357

16. Ahn SJ, Ryu SJ, Joung JY, Lee BR (2017) Choroidal thinning associated with hydroxychloroquine retinopathy. Am J Ophthalmol 183:56-64

17. de Sisternes L, Hu J, Rubin DL, Marmor MF (2016) Analysis of inner and outer retinal thickness in patients using hydroxychloroquine prior to development of retinopathy. JAMA
Ophthalmol 134(5):511-519. https://doi.org/10. 1001/jamaophthalmol.2016.0155

18. Allahdina AM, Stetson PF, Vitale $S$ et al (2018) Opticalcoherencetomographyminimumintensity as an objective measure for the detection of hydroxychloroquine toxicity. Invest Ophthalmol Vis Sci 59:1953-1963

19. Maturi RK, Yu M, Weleber RG (2004) Multifocal electroretinographic evaluation of long-term hydroxychloroquine users. Arch Ophthalmol 122:973-981

20. SebastianiS, Fresina M, Cellini M, CamposEC (2017) Hydroxychloroquine for treatment of rheumatoid arthritis: multifocal electroretinogram and laser flare-cell photometry study. Clin Ophthalmol 11:689-696

21. Xiaoyun MA, Dongyi HE, Linping HE (2010) Assessing chloroquine toxicity in RA patients using retinal nerve fibre layer thickness, multifocal electroretinography and visual field test. $\mathrm{Br} \mathrm{J}$ Ophthalmol 94:1632-1636

22. Ahn SJ, Ryu SJ, Lim HW, Lee BR (2019) Toxic effects of hydroxychloroquine on the choroid: evidence from multimodal imaging. Retina 39(5):1016-1026. https://doi.org/10.1097/IAE. 0000000000002047

23. Marmor MF, Kellner U, Lai TYY, American Academy of Ophthalmology et al (2016) Recommendations on screening for chloroquine and hydroxychloroquine retinopathy (2016 revision). Ophthalmology 123:1386-1394

24. The Royal College of Ophthalmologists (2018) Clinical guidelines. https://www.rcophth. ac.uk/standards-publications-research/clinicalguidelines/.Zugegriffen: 30. Dez. 2018

25. Chatrel $C$, Roubille $F$, Vernhet $\mathrm{H}$ et al (2018) Cardiac complications attributed to chloroquine and hydroxychloroquine: a systematic review of the literature. Drug Saf 41:919-931

26. Tselios K, Deeb M, Gladman DD et al (2019) Antimalarial-induced cardiomyopathy in systemic lupus erythematosus: as rare as considered? JRheumatol 46:391-396

27. Durcan L, Clarke WA, Magder LS, Petri M (2015) Hydroxychloroquine blood levels in systemic lupus erythematosus: clarifying dosing controversies and improving adherence. J Rheumatol 42:2092-2097

28. Yeon Lee JL, Jennifer KK, Seung HJ et al (2017) Factors related to blood hydroxychloroquine concentration in patients with systemic lupus erythematosus. Arthritis Care Res 69:536-542

29. Bethel M, Yang FM, Li S et al (2016) Hydroxychloroquine in patients with systemic lupus erythematosus with end-stage renal disease. J Investig Med 64:908-910

30. Miro O, Pedrol E, Casademont J et al (1996) Muscle involvement in rheumatoid arthritis: clinicopathological study of 21 symptomatic cases. Semin Arthritis Rheum 25:421-428

31. Casado E (2006) Antimalarial myopathy: an underdiagnosed complication? Prospective longitudinal study of 119 patients. Ann Rheum Dis 65:385-390

32. Mascolo A, Berrino PM, Gareri P (2018) Neuropsychiatric clinical manifestations in elderly patients treated with hydroxychloroquine: a review article. Inflammopharmacology 26:1141-1149

33. Jourde-Chiche N, Mancini J, Dagher N et al (2012) Antimalarial ototoxicity: an underdiagnosed complication? A study of spontaneous reports to the French pharmacovigilance network. Ann Rheum Dis 71:1586 (Table 1) 
34. Costedoat-Chalumeau N, Hulot J-S, Amoura Z et al (2007) Heart conduction disorders related to antimalarials toxicity: an analysis of electrocardiograms in 85 patients treated with hydroxychloroquine for connective tissue diseases. Rheumatology (Oxford) 46:808-810

35. Godeau P, Guillevin L, Fechner J et al (1981) Disorders of conduction in lupus erythematosus. Frequency and incidence in a group of 112 patients (author's transl). Ann Med Interne (Paris) 132:234-240

36. Bahloul E, Jallouli M, Garbaa S et al (2017) Hydroxychloroquine-induced hyperpigmentation in systemic diseases: prevalence, clinical features and risk factors: a cross-sectional study of 41 cases. Lupus 26:1304-1308

37. Götestam Skorpen $C$, Hoeltzenbein $M$ et al (2016) The EULAR points to consider for use of antirheumatic drugs before pregnancy, and during pregnancy and lactation. Ann Rheum Dis 75:795-810

38. Klinger G, Morad Y, Westall CA et al (2001) Ocular toxicity and antenatal exposure to chloroquine or hydroxychloroquine for rheumatic diseases. Lancet 358:813-814

39. Motta M, Tincani A, Faden D et al (2005) Followup of infants exposed to hydroxychloroquine given to mothers during pregnancy and lactation. JPerinatol 25:86-89

40. Wagner N, Assmus F, Arendt G et al (2019) Impfen bei Immundefizienz: Anwendungshinweise zu den von der Ständigen Impfkommission empfohlenen Impfungen. (IV) Impfen bei Autoimmunkrankheiten, bei anderen chronischentzündlichen Erkrankungen und unter immunmodulatorischer Therapie. Bundesgesundheitsblatt Gesundheitsforschung Gesundheitsschutz 62:494-515 